\title{
THE ENGAGE MODEL: A FACILITATOR'S FRAMEWORK FOR LEARNER ENGAGEMENT
}

\author{
Dr Sheela Philip \\ Associate Professor, St Teresa's Institute of Education, Mumbai
}

Article DOI: $\underline{\text { https://doi.org/10.36713/epra6711 }}$

DOI No: 10.36713/epra6711

\begin{abstract}
Give the pupils something to do, not something to learn; and the doing is of such nature as to demand thinking; learning naturally results. John Dewey

Teachers, as facilitators of learning, are constantly soul searching, looking for sound transaction styles that are known to raise teacher efficiency. Making classrooms spaces that are joyful, learner-centric and engaging requires enormous portions of ingenuity on the part of a teacher. 'Learning-by-Doing' is a psychologically robust way of learning. It not only etches lasting memory but also makes the process of learning a meaningful experience. Self-learning within groups instils lessons on collaborative and social discipline and thus prepares the learner to face adversity in preparation for life. An effective curriculum should provide for multiple intelligences to fruition, thus raising correlation between subjects, providing scope for every student to engage in the act of discovery. Unplugged education, outdoors education, learning through engagement are all hands-on strategies that are novel and significant in holding attention levels in an era that is overwhelmed by technology and digitisation. The 'STEAM Curriculum' holds great relevance in contemporary education and it stems from learning engagements advocated by this model, permitting multidisciplinary correlation and reflection on action.

This paper provides the framework of a lesson that is transacted hands-on through inquiry and reflection. It provides a prospective teacher of this model with the syntax and the pathway of deliberation. This is a general prototype that bears a multidisciplinary essence and thus can be extrapolated in varied situations, levels and academic disciplines of learning.

KEYWORDS: Discovery Method, ENGAGE Model, Experiential Learning, Pragmatism, STEAM curriculum
\end{abstract}

\section{INTRODUCTION}

In Europe and the United States of America, the 19th century was regarded as an age of creative dynamism. The Industrial Revolution heralded the entry of nascent concepts such as Democracy and Industrialisation into the educational deliberations as they were understood to be significant precursors of economic progress. Embracing science and technology in the arena of industry ushered in newfound prosperity, raising standards of living among the mushrooming societies. This triggered a new wave of human immigrants into the continent of America, impacting the transaction style of education within the emerging plural and diverse communities.

The nineteenth century saw the crystallisation of several sublime ideologies put forward by European thinkers and scholars, questioning the creditworthiness of Western education. Philosophers and psychologists frowned upon the schooling system that certified the learner as academically potent who in reality seemed unenlightened. Productivity reflected an upward economic trend; however the lives of people were impoverished. Unanimous collective wisdom among the scholarly pointed to the fact that instruction at school failed to cater to individual differences among heterogeneous groups of people, pedagogy was constructed on a framework that was ill-researched and rigid, that it failed to generate the desirable outcomes of schooling.

John Dewey, an American philosopher, embracing the Pragmatic school of thought, advocated experiential learning, which endorses learning by 
doing, where the role of a teacher is to curate an environment that nurtures self-learning through engagement. This in turn leads to discovery learning. $\mathrm{He}$ is heralded as the most influential educator and philosopher of the twentieth century for his views on progressive education.

The Laboratory School established by Dewey in 1896 at the University of Chicago bears testimony to his strong belief in the Discovery Method. His ideology pivoted on democratic education that was collaborative: where conjoint, cooperative activity among learners would enable them with social skills and efficiency that would lead to self-reliance. This premise was hailed by Dewey's student, Professor William Kilpatrick, who reposed great trust in 'learning by doing'. Kilpatrick propounded the Project Method, practiced in experimental schools that are student-driven and where 'inquiry and reflection' are rewarded. Such education is understood to empower the learner in his socialisation process, thus preparing for life.

This model that I have curated is structured on Dewey's Discovery Model of learning. It is a versatile learning model framework for facilitators and mentors across disciplines. The syntax of the model highlights the subtle yet responsible role that a teacher plays in reaching out to each student in the learning cohort.

\section{The ENGAGE Model}

The syntax of learning through experiential learning and discovery has been elaborated upon below, using the acronym ENGAGE.

\section{Phase 1:}

EXPOSURE: This model strives to provide the learner with contrived experiences and thus the educator must pay heed to providing the learner with a panoramic canvas that can showcase variables of learning that are distinct. It is important that we take into consideration the learning styles, attitudes, aptitudes, interests, passions, levels of curiosity, intellectual states of mind, and so on in a learner. The wider the flexibility the engagement permits, greater is the funneling of learning. The educator should ensure that the task at hand is novel; this will then provide the external stimulus that can spark internal curiosity and motivation, which will goad the learner to proceed with complete immersion in the task at hand. This model will fruition into an abundance of positive outcomes when the learners are placed in a conducive learning environment or group. Needless to say that the task at hand should be meaningful to the learner. The outcome of the task paves way to an eclectic collage of ideations, deriving its essence from multiple designs of learning. The model is best practiced as a group activity and it exalts team spirit and collective wisdom.
Completion of the task entails experiential learning, cooperative learning, collaborative learning, discovery learning... all well-integrated into a trans-disciplinary learning style.

\section{Phase 2:}

NAVIGATE: This phase does the spadework of scaffolding the group with instructions and guidelines, illuminating the group regarding the task at hand. The scope of the activity is defined by streamlining the limitations, setting delimitations, and charting geographic jurisdictions within which the task should navigate. Interaction during this stage is initiated by dialogue and it encourages a free flow of ideas and queries. No question that comes up is considered insignificant and the group is empowered with the motivation that would see them through the activity. This is also considered a warm-up stage, where roadblocks are cleared and the facilitator prods the group dynamics to set rolling. At this stage care is taken to ensure that the group is emotionally bound cohesively with right relationships that would help in facing challenges and gaining self-knowledge. This mentoring is considered vital as it aims to guide students to navigate through dialogue, enquiry and critical thinking. The group is taught to nurture consideration within groups and to curate creative intelligence. This is an exercise that demands selfdiscipline.

\section{Phase 3: GATHER DATA:}

At this stage, the peers work in tandem engaged in self-reflection. This promotes an insightful surge of collective wisdom and prudence; thus the group collectively pursues a common goal. It is at this stage that emotions of we-feeling are best experienced within the group. To each member the task seems light as the yoke rests on several shoulders. Garnering of individual strengths to pool in the best data comes to the fore. Each task demands a set of multiple intelligences that enables every member of the group to have a contributory role in the attainment of the task. The satisfactory completion of this instils a feeling of selfempowerment. Division of labour and raised selfesteem surface within groups. The transparency in the group interaction raises the accountability of its members. The educator's subtle and unarticulated presence within the group ensures credibility to the work in progress. The focus here is on creating a heap of authentic, researched epistemology.

\section{Phase 4:}

AUGMENT:

During this phase, the group converges to assimilate 
the theoretical elaborations gathered as data. Valuable pertinent information derived is then augmented contextually to offer social relevance. Intellectual deliberations within the group are used to provide an analysis, causing a systematic unfurling of understanding. This stage is significant as it enables members of the group to offer justifications as personal insights. The analysis initiates and sustains dialogue, leading to comprehension. This in turn raises the selfworth of the group as the assigned task is rendered lucid and emerges with refinement. The work is now ready for projection. This is the most significant as it directly impacts the purpose of the activity.

\section{Phase 5:}

\section{GUSH:}

It is at this stage that the members of the group actually bask in the glory of their endeavour. Members are given a chance to enlighten with exaggerated enthusiasm their personal learning insights. Stress should be paid to ensure that the outcome of this learning engagement is ready for extrapolation in new and unseen situations. Personal testimonies, recounts are voiced within one's small group and then broadcast as outcomes of the engagement to the larger cohort. This phase showcases the worthiness of the discovery made through collaboration and the accomplishment of this cooperative exercise.

\section{Phase 6: ENVISAGE:}

It is the windup stage; however, it is a significant step as the experiences are etched as outcomes of the task assigned. The report handed in by the cohort is valuable as it would throw light on the deliberations made by the group. The effectiveness of this activity is immortalised as a research finding and the epistemology envisaged by the group is shared for the larger good. To members of the group, practical engagement would probably be the first and often the right step in the pursuit of their passion.

\section{Prototype ENGAGE Model (A Learning Engagement Plan) \\ Level: Higher Education \\ Objective of the Task: To carry out a 'Green Audit' of your educational campus \\ Methodology / Design: Experiential learning (hands-}

on), Collaborative Learning, Cooperative learning, Correlational learning, Discovery Method

Approach: Multi-disciplinary. Use of the educational apps, Self-directed learning, Spiritual reflections

Pedagogy Correlations: Literature, Technology, Science, Environmental Studies, History, Geography, Mathematics, Holy Scriptures

\section{Expected Outcomes of the Task:}

1) The student collates data from the assigned geographical region (college campus) assigned for the task.

2) The student comprehends the use of the technological app (e.g., Plant Finder)

3) The student gathers authentic counts of the vegetation in the campus.

4) The student compiles a green audit of his / her campus.

5) The student reflects on his / her role as a responsible environmental steward and draws up a personal narrative on environment conservation through environment consciousness (not less than 700 words)

6) The student engages in self authenticating and documenting the 'work-in-progress' using Geo-tagged pictures

7) The student engages in collating comparative insights on the indegenous green cover of the region along a timeline.

8) The student is introduced to a healthy outdoors leisure activity that is of critical importance to the learner's immediate future.

\section{Instructions to Learners:}

1) Download the apps of your choice that would enable you to identify vegetation e.g., 'Plant Finder' and geotag the pictures that you take e.g., with 'Geotag Camera' from 'Play Store'.

2) Identify vegetation growing in the region allocated to you using the app e.g., 'Plant Finder'.

3) Tag the plant in the campus once it has been numerically accounted for to ensure accuracy of count.

4) Classify data gathered on the green cover (vegetation) into a spreadsheet.

5) Authenticate your role in this engagement using geotagged pictures.

6) Create a reflective text on the relevance of this exercise. 


\begin{tabular}{|c|c|c|c|c|c|c|c|c|c|c|c|}
\hline \multicolumn{12}{|c|}{ Name of Campus Site: College Backyard } \\
\hline \multirow[b]{2}{*}{$\begin{array}{c}\text { Serial } \\
\text { Number }\end{array}$} & \multirow[b]{2}{*}{ Name of Plant } & \multicolumn{3}{|c|}{ Vegetation } & \multirow[b]{2}{*}{$\begin{array}{c}\begin{array}{c}\text { Number of } \\
\text { Plants }\end{array} \\
\end{array}$} & \multicolumn{2}{|c|}{ Ongin } & \multicolumn{2}{|c|}{ Type } & \multicolumn{2}{|c|}{ Life in Years } \\
\hline & & Tree & Shrub & Herb & & \begin{tabular}{|c|} 
indigenouse \\
Native
\end{tabular} & Cultivated & Deciduous & Evergreen & Perennial & Annual \\
\hline 1 & $\begin{array}{l}\text { Manglera indica } \\
\text { (Mango) }\end{array}$ & $Y$ & N & N & 1 & $Y$ & N & $\mathrm{N}$ & $Y$ & $Y$ & N \\
\hline 2 & Musseanda & $r$ & $\mathrm{~N}$ & $\mathrm{~N}$ & 2 & N & $\checkmark$ & $\checkmark$ & N & $r$ & N \\
\hline
\end{tabular}

\section{Operational Definitions of terms related to} the task:

1. Trees : Woody perennial plants, typically having a single stem or trunk and bearing lateral branches and leaves. Their stems are more than 2 inches in diameter and have attained a height of more than 3 feet.

2. Shrub : A woody plant, smaller than a tree and having several main stems arising at or near the ground. Their stems are less than 2 inches in diameter and have attained a height of less than 3 feet.

3. Herb : Any plant bearing leaves, seeds or flowers. That does not have a woody stem and that dies down to the ground after blooming.

4. Deciduous : Vegetation that sheds leaves seasonally or annually.

5. Evergreen Trees : Vegetation that are nondeciduous. Those that do not shed leaves.

\section{Discussion of the Model}

Premise: This model takes into account that learners are highly motivated to engage in activities within groups. Peer learning strengthens cohesive bonds among learners, resulting in positive learning outcomes. Learners today are digitally savvy and the incorporation of technology in education eases the demands made by traditional teaching. Outdoors education and unplugged education is a welcome shift from education that is heavily dependent on technology, right through the stages of instruction. Responsible decision making skills can stem from 'Reflection-in-Action' and 'Reflection-on-Action'.

Mentoring here demands an in-depth understanding of each student's strengths and weaknesses. Teachers deliberate differently with each ward, judiciously raising insightful advances in the arena of learning. Teachers should also be aware of individual learner capacities and augment it with the help that can be garnered from peer mentors. Here, it is of importance that teachers understand the $80: 20$ ratio of the Pareto Principle and use it to one's advantage. This implies that the teacher is not the only instructor in the learning group. Such practices demand great ingenuity and resilience from teachers. However, the dynamic sociometry such engagements initiate and sustain are a source of gratification to a teacher who dares to venture into the style propagated by the discovery method.

\section{BIBLIOGRAPHY}

1. Janse, B. (2019). John Dewey Theory. https://www.toolshero.com/changemanagement/john-dewey-theory/ (Retrieved April 25, 2021)

2. https://educationalresearchtechniques.com/2015/07 /27/william-kilpatrick-the-project-method/ (Retrieved April 25, 2021)

3. Chambliss, J.J. (2003). John Dewey's Philosophy of Education Before "Democracy and Education". Education and Culture, 19(1), 1-7. Retrieved April $2021 \quad$ from http://www.jstor.org/stable/42922466 